\title{
VIEWERS' LANGUAGE STYLES ON GOLD DIGGER: A MULTIMODAL ANALYSIS
}

\author{
${ }^{1}$ Neny Namirah \& ${ }^{1,2}$ Didin Nuruddin Hidayat \\ ${ }^{1}$ Department of English Education, UIN Syarif Hidayatullah Jakarta, Indonesia \\ ${ }^{2}$ Corresponding Author Email: didin.nuruddin@uinjkt.ac.id
}

\begin{tabular}{|c|c|}
\hline Article Info & Abstract \\
\hline $\begin{array}{l}\text { Article History } \\
\text { Received: February } 2021 \\
\text { Revised: March } 2021 \\
\text { Published: April } 2021\end{array}$ & $\begin{array}{l}\text { This paper undertakes viewers' languages style on gold digger using a } \\
\text { multimodal analysis. This paper aims to depict the language style of viewer } \\
\text { comments on Gold Digger prank in YouTube channel content. Comments on the } \\
\text { contents of YouTube channel may differ from active viewers, and the language }\end{array}$ \\
\hline $\begin{array}{l}\text { Keywords } \\
\text { Discourse analysis; } \\
\text { Language style; } \\
\text { Multimodal analysis; }\end{array}$ & $\begin{array}{l}\text { style they utilized shows the culture, the background, or class where they are } \\
\text { from. Therefore center on language style constitutes the main point of this study. } \\
\text { The corpus was achieved by viewers' comments on the gold digger prank as one } \\
\text { of the YouTube channel contents. The study employed a descriptive qualitative } \\
\text { research approach and the content or viewers comments on YouTube as the form } \\
\text { of data. The study will focus on the viewers' style language in commenting on the } \\
\text { prank content called Gold Digger in the YouTube channel and the style language } \\
\text { that the viewers mostly utilized multimodal analysis. Casual style is the dominant } \\
\text { style conveyed by the viewers. The viewers' language style varies on the bases of } \\
\text { the intimacy, the social interaction and the community from which they come, and } \\
\text { the media in which they share their thoughts. }\end{array}$ \\
\hline
\end{tabular}

How to cite: Namirah, N., \& Hidayat, D.N. (2021). Viewers' language styles on gold digger: A multimodal analysis. JOLLT Journal of Languages and Language Teaching. 9(2), 236-242, DOI: https://doi.org/10.33394/jollt.v\%vi\%i.3508

\section{INTRODUCTION}

Language is a device to communicate with others. Without language, humans have difficulty interacting with others. Language is the most significant part of social life (Renkema, 2004). Everyone needs to comprehend language variations and styles to avoid misunderstanding between them in society. Currently, most Indonesian people use social media as part of their life, especially for teenagers. This has become an issue of great importance recently because social media is a means of their communication to socialize with each other. They can create and share many social media things about their activities, feelings, experiences, and many things in their life such as photos, audio, or video. Social media platforms represent a new place where people, organizations, and even governments can commercially, socially, politically, and educationally interact with each other and exchange information, thoughts, products, and services (Alalwan, 2018; Joe \& Anto, 2018; Li, 2017; Ratnasari et al., 2019; Westenberg, 2016). Social media has attracted teenagers to use it in their everyday life. Furthermore, they can spend most of their time just using their gadget for hours and even neglecting their family, their surroundings, and even their school tasks. Freitas (2016) stated that people are losing sight of the things that ground our life in connection and love, in meaning and relationships. On the other hand, social media is beneficial as a source of information. It is used online, and they need to have an account to use it. The social media mostly used by teenagers are WhatsApp, Facebook, Twitter, Path, Line, YouTube, etc. (Meeker, 2019).

YouTube is a popular website for social media that offers various videos such as video clips, movies, and videos developed and made by YouTube users themselves (Brook, 2011; Fleck et al., 2014). We can watch YouTube on this social network by watching motion pictures. People now use YouTube to convey feelings through music videos and even films that describe 
other regions' experience or culture. Not only for those things but also for making and producing funny and romantic videos. Funny videos or usually called "Prank," can mostly be watched on YouTube. The one who uses and creates or makes content is called YouTubers. Some individuals are interested in becoming a YouTuber because they can get royalties from it when posting their videos and attracting several viewers or subscribers.

In YouTube video material, a practical joke or prank has become more popular in recent years. To make a fool of someone or group to make a joke, people use YouTube. A prank is a mischievous prank played on others, which normally causes the victims to be humiliated, puzzled, confused, or uncomfortable. A person who performs a practical joke is called a "practical joker." Any separate comments on the prank's content made by YouTubers suggest that audiences on YouTube will make constructive and negative or even encouraging comments on the content of the prank. The "Gold Digger" prank is one of the contents in YouTube that depicts a person who likes or dates others because of how much money they have rather than love. Gold Digger is a woman who explicitly desires material and economic benefits above all else and who is willing to exchange sex for it (Stephens \& Phillips, 2003). The amount of comments made by viewers relates to the content. They use a variety of language styles to express feedback about the prank that readers will understand.

Language has various styles, and its style plays a significant role in comprehending the meaning of social communication in language to provide the purpose of social interaction. Style focuses on verbal communication methods - how speakers use the language variety resource to make sense of social experiences (Coupland, 2007; Ross \& Coleman, 2010). Using different styles makes it easier to understand, as well as by whom the language is spoken. Several levels of style utilized by people distinguish among several degrees of difference (Epstein, 2003). In linguistic, language style is included in semantic scope. It has five styles. They are frozen, formal, intimate, consultative, and casual.

The present study intends to investigate the types of language styles used in YouTube viewers employing multimodal analysis to analyze the language types used in viewers' comments of gold digger prank comments and generate interest. The study aims to analyze viewers' language style in YouTube channels in gold digger prank content. Furthermore, the study seeks to investigate the most language styles used in viewers' chats about gold diggers' prank content.

In recent years there have been significant studies that addressed discourse analysis of language style. The writer observed several studies which have similarity to this present study as reference. Three studies had been conducted. The first is a Style And Language of Inequality in The Movie "The King's Speech" written by (Karim, 2014). This study is focused on how a particular linguistic variable gets associated in the popular mind with a particular variety. This study utilized a qualitative approach to depict the use of language used by the king in the movie. She described how the language and speaking ability has its own power.

Another study by Nyagaka and James (2014) examined adverts associated with business premises, vehicles and institutions in languages like English, Kiswahili and Ekegusii found in the two towns of Kisii and Keroka. These adverts are studied in terms of context, content and invitation or persuasion potential using the semiotics linguistic landscape (LL) for easier categorization. They employ Sperber and Wilson theory of Relevance (RT) focusing on the narrowing and broadening of words' meanings, disambiguation, and adding of social meaning; and presuppositions in the language that formulate information and strategy of advertising

Furthermore, similar work has also been pursued by Misauri (2018). Although differing in practice, the methods are conceptually the same. He conducted the study of Analysis of Colloquial Expressions in Gold Digger Prank and used a descriptive qualitative method. The author discovers the colloquial expressions and analyzes the significance of the colloquial expressions found in the Gold Digger Prank film. This study's data are in the form of words, 
phrases, and sentences containing the colloquial expressions contained in the film. The author inferred from the review and finding that the colloquial expressions are regarded as impolite and rude language since they are casual or informal language or ordinary language.

These three studies have similarities and differences with this present study. First, compared to the research conducted by (Karim, 2014), the object of the study is The King Speech. He analyzed the style and language in the movie "King's Speech while the object of this study is Viewers comments on the gold digger prank in the Youtube channel and focused on analyzing the viewers' language styles. The previous study focused on how special linguistic variables are associated in the popular mind with various elements. By contrast, the research study focuses on analyzing the language used styles, whether it a frozen style, deliberative style, consultative style, casual style, or intimate style. Second, compared to the research conducted by Nyagaka and James (2014), this study's object is different as well. They utilized semiotics linguistic landscape (L L) for easier categorization and applied Sperber and Wilson theory of Relevance (RT), focusing on the narrowing and broadening of words' meanings, disambiguation, and adding of social meaning; and presuppositions in the language that formulate information and strategy of advertising. On the other hand, this recent study used modality analysis to analyze the texts. Third, Misauri (2018) focused on the analysis of colloquial expressions in gold digger prank. The author analyzed the meaning of colloquial expressions found in the Gold Digger Prank video and achieved the data of this research using words, phrases, and sentences containing colloquial expressions found in the video. By contrast, this study focused on the phrases or sentences utilized by the viewers in the gold digger video in the Youtube channel and analyzed based on the language styles.

Based on the background above, the present research endeavored to address the following questions: What the language styles are utilized by the viewers in Gold Digger Prank in the YouTube video and what factors influence the language styles utilized by the viewers in Gold Digger Prank YouTube video. The study results are expected to provide useful information for the YouTube prank channel viewers to be wiser in providing comments because all people in Indonesia read all the comments. For YouTube Content creators, the study results are expected to choose significant content in the video and provide educated content because the viewers are common people and kids who still sit in schools. Finally, the study's result is expected to reference other researchers as the basic consideration to implement further research.

\section{RESEARCH METHOD}

The present study employed a descriptive research method in a multimodal analysis of viewers' comments on Gold Digger's prank prank. The details in this study were verbal texts embedded in the viewers' comments on the prank's content. Words, phrases, clauses were the components of the verbal texts in the viewers' comments. There are thirteen phrases and clauses that were analyzed. Five numbers are clauses, three numbers are imperatives sentences, and two are affirmative sentences. The last three are phrases. There are hundreds of comments, but the researchers only took thirteen phrases, words, or clauses representing the language styles.

The researchers watched prank material on the YouTube site. Then, the written text in the form of discourse is taken from the comment of viewer chats of YouTube channel, and it is in the form of a YouTube channel titled "Gold Digger Prank Part 11". Thus, the researchers categorized per sentence, phrase, or clause based on the language styles' five characteristics. After that, the researchers elaborated and depicted how the viewers employed the language styles and the most frequently used language styles after seeing the gold digger YouTube page's contents. Having classified based on the language styles, the researchers found out the factors that influence the viewers' language styles. 


\section{RESEARCH FINDINGS AND DISCUSSION}

The researchers present the data taken from the viewers' comments from Gold Digger YouTube channel in these findings. The data are presented in words, sentences, clauses, and utterances. It is categorized and analyzed based on Martin Joss's theory that focuses on viewers' comments on gold digger prank part 11! Hooman TV.

The researchers found many data appropriate to the language styles and took only 13 comments. Then, the data were divided into four types of language styles as presented as follows.

Table 1

Kinds of Language Styles found in "Gold Digger Part 11!Hooman TV

\begin{tabular}{|c|c|c|c|}
\hline Language Styles & Viewers Comments & $\begin{array}{l}\text { Number of } \\
\text { Occurrences }\end{array}$ & Percentage \\
\hline Frozen Style & $\begin{array}{l}\text { 1. This is how many gold diggers are on this earth. } \\
\text { 2. This is how many people hate gold digger } \\
\text { 3. Whenever a girl asks whether it is your car, she } \\
\text { is definitely a gold digger }\end{array}$ & 3 & $0.23 \%$ \\
\hline Formal Style & - & 0 & \\
\hline Casual Style & $\begin{array}{l}\text { 1. "I'm just a little shyyy" } \\
\text { 2. When mouse sees the cheese, when gold digger } \\
\text { sees money. Damn, two gold diggers exposed } \\
\text { at the same time. } \\
\text { 3. Green motherfuc... secree but nice video } \\
\text { though. } \\
\text { 4. Hooman, Do more gold digger pranks! Love } \\
\text { the cars also bro! Damn! I need a car. } \\
\text { 5. Damn, two gold diggers exposed at the same } \\
\text { time. } \\
\text { 6. Aah, the famous line }\end{array}$ & 6 & $0.46 \%$ \\
\hline Consultative Style & $\begin{array}{l}\text { 1. Bring these gold diggers in expensive restaurant } \\
\text { and left them with a check. } \\
\text { 2. Do more gold diggers pranks }\end{array}$ & 2 & $0.15 \%$ \\
\hline \multirow[t]{2}{*}{ Intimate Style } & $\begin{array}{l}\text { 1. The cars are looking better than the girls. } \\
\text { 2. My dream is to own that Mclaren when I am } \\
\text { older. }\end{array}$ & 2 & 0.15 \\
\hline & total & 13 & $100 \%$ \\
\hline
\end{tabular}

The researchers found four language styles that are used in viewers comments in Gold Digger Part 11! There are Frozen language, Casual language, Consultative Language, and Intimate style. The data yielded by this study as follows.

\section{Frozen Style}

1. This is how many gold diggers are on this earth.

2. This is how many people hate gold digger

3. Whenever a girl asks whether it is your car, she is definitely a gold digger

The viewers' comment above consists of language style and is justified as a frozen style used in a very formal situation. The comment provides in-depth and brief information and is stated by a professional. The tone of the expression used is very strong, reflecting formality. It seems as though the viewers have experienced the mindset of gold diggers in various videos from various cultures to elaborate on the perception of what they have witnessed and observed in their local societies. 


\section{Casual Style}

1. "I'm just a little shyyy"

2. When mouse sees the cheese, when gold digger sees money. Damn, two gold diggers exposed at the same time.

3. Green mother fuc...secret but nice video though.

4. Hooman, Do more gold digger pranks! Love the cars also bro! Damn! I need a car.

5. Damn, two gold diggers exposed at the same time.

6. Aah, the famous line

The sentence in the viewers' comment above uses casual language. The viewers convey a casual language used among friends, co-workers, or strangers when an informal atmosphere is appropriate. Here she writes a very short comment and provides a word of shyyy to show that the video is actually a media that all of the level can be seen and watched. Hence, she is free to use the language in the utterance in the video.

\section{Consultative Style}

1. Bring these gold diggers in expensive restaurant and left them with a check.

2. Do more gold diggers pranks

The viewer comments above uses consultative style. Consultative is generally employed in a semi-formal communication situation. It is also used orally to conduct everyday business. Language used in negotiating with strangers, distant acquaintances, or colleagues of unequal rank. In these comments the viewer provides some ideas to the hooman to have a better idea in creating the content for gold digger content by suggesting the chance of taking the gold diggers to a fancy restaurant and leaving them with a bill.

\section{Intimate Style}

1. The cars are looking better than the girls.

2. My dream is to own that Mclaren when I am older.

The viewer comments above are classified into intimate style. It narrates the a completely private language developed within families and the closest friends. They convey the comment as if the youtube creator is like family and close friend. They utilized polite utterances and response based on feeling and attitude without hurting or underestimate others. Coupland (2007) using a particular feature, a speaker might style himself or herself as, for example, more or less powerful within a particular relationship, or style the relationship as being a more intimate or less intimate one.

This paper examines the gold digger language style using a multimodal analysis. This paper aims to represent the language style of the viewer's comments on the Gold Digger prank in the YouTube channel's material. Comments on the YouTube channel contents vary from those of active viewers, and the language style used reflects the history, context, or class from which they come. Here the explanation of the findings was depicted as follows:

\section{Language styles that utilized by the viewers in Gold Digger Prank in YouTube video}

The description of the data collected through the classification showed that casual style, frozen style, formal style, consultative style, and intimate style were the viewers' language styles. It is supported by the number of occurrences shown in Table 1 Kinds of Language Styles found in Gold Digger Part 11! Hooman TV. The casual style, as shown in Table 1, showed $0.46 \%$ of occurrences. The data showed that viewers used more casual styles than other styles. Any of this supports the majority of occurrences in table 1.

In the public comments on the YouTube channel video, people's casual style lets them feel free to say what is on their minds and without feeling afraid or intimidated. It is in line with Zulaekho (2011), who stated that Casual style has four characteristics: the use of nickname when addressing one another, rapid and slurred pronunciation, the use of slang, and the use of non-standard forms. From the findings, the sentence Hooman, Do more gold digger pranks! Love the cars also, bro! Damn! I need a car, is one of the casual styles because the viewer 
provided advice and suggestion to the creator of the YouTube channel of Gold Digger, the Hooman to perform more gold digger pranks. The sentences showed an informal situation as if the viewers were talking to his friend, making the public viewers more relaxed to comment even dared to use slang language.

On the other side, based on table 1 presented in the findings, Frozen style had $0.23 \%$ of occurrences. As the second number of the most occurrences. It indicated that viewers used the language style in brief and professional-stated detail. The sound of the used expression is very strong, indicating formality. From the statement in the findings, This is how many gold diggers are on this earth, is one of the viewer's frozen language style in public comment of YouTube channel video. The viewer used the most formal style and had symbolic value. Furthermore, The viewer commented about the condition of gold diggers in this era and seemed to have observed gold diggers in his region. To understand speaking and style as sociolinguistic processes, we need to understand the idea of social organisation that integrates a situational and cultural context (Arizpe et al., 2014; Coupland, 2007). The viewer used lengthy and deliberate sentence constructions and nearly no reactions between the viewer and the others.

According to the description in the findings above, the study also explained that both the consultative and the intimate style had the same number of occurrences. Consultative and Intimate style had $0.15 \%$ occurrences. The consultative style implied that the authors used sentences, phrases, or clauses to show a semi-formal interaction condition. It is used orally to conduct daily business activities as well. Language used to negotiate with strangers, distant acquaintances, or unequally ranked colleagues. The findings statement, Bring these gold diggers in expensive restaurants and left them with a check, tells about a suggestion to bring the gold diggers to a fancy restaurant and let them pay for it. The sentence gives an idea or the way for the content YouTuber to do another activity for the gold diggers. The comment also showed the distance between the YouTuber and the viewer, so the language style used is semiformal interaction. This condition was also approved by Indra and Hamzah (2018); in a consultative style, people tend to consider what they write in order to be understood by other people. They are not only thinking about what they feel but also the content of their comments.

Another $15 \%$ of occurrences were intimate style, implying that the viewers' language was respectful and offered a comment focused on feeling and mood without harming or underestimating others. On the other hand, in Table 1 above, formal style was rare to be used by the viewers in commenting on the content of the YouTube video Gold Digger Part 11. Since the content of the YouTube video is shown for amusement, the comments made in public are just for enjoyment. Based on the results obtained as reported in the above findings, it is revealed that the viewers used four language types. The use of language types showed the factors that affected them, such as familiarity, closeness, social connection and community, class, and professionalism.

\section{CONCLUSION}

This study is conducted to find the language styles used in Gold Digger content of prank in YouTube channel. The data yielded by this study can be concluded that from the five language styles proposed by Martin Joss there are $0.46 \%$ used casual styles in viewers comment, frozen style $0.23 \%$, Consultative $0,15 \%$, and Intimate $0.15 \%$. Casual styles is the most dominant one conveyed by the viewers. Most comments that conveyed as if they were chatting with their friends, acquaintances, and insiders are why they use slang, ellipses, and verbal formulas. The viewers' language style differs based on the intimacy, the social relationship and the culture where they come from, and the media where they express their thoughts. Because YouTube is a social network where people do not communicate personally, they are free to make remarks without a propensity and even fear of being replied to or contradicted, or even scolded by the Youtuber content. 
The result of this research does not cover all kinds of language styles. However, this is still far from the complete one. By this study, the researchers expect to help people interested in discourse analysis, especially in gold digger comments. Moreover, the data can be useful for YouTuber content creators to create more creative content. The viewers can help them be more alert in conveying some comments, especially the language styles. Further analysis can examine the viewers' comments on a very formal speech by someone who has a significant status and has an excellent influential effect on others.

\section{REFERENCES}

Alalwan, A. A. (2018). Investigating the impact of social media advertising features on customer purchase intention. International Journal of Information Management, 42, 6577. https://doi.org/10.1016/j.ijinfomgt.2018.06.001

Arizpe, E., Bagelman, C., Devlin, A. M., Farrell, M., \& McAdam, J. E. (2014). Visualizing intercultural literacy: engaging critically with diversity and migration in the classroom through an image-based approach. Language and Intercultural Communication. https://doi.org/10.1080/14708477.2014.903056

Brook, J. (2011). The affordances of YouTube for language learning and teaching. Hawaii Pacific University TESOL Working Paper Series, 9(1,2), 37-56.

Coupland, N. (2007). Style: Language variation and identity. Cambridge University Press.

Epstein, E. L. (2003). Language and style. Routledge.

Fleck, B., Beckman, L., Sterns, J., \& Hussey, H. (2014). YouTube in the classroom: Helpful tips and student perceptions. Journal of Effective Teaching, 14(3), 21-37.

Freitas, D. (2016). The happiness effect: How social media is driving a generation to appear perfect at any cost. Oxford University Press.

Indra, I., \& Hamzah, H. (2018). An analysis of language style of teenagers found in Facebook status. English Language and Literature, 7(1), 98-105.

Joe, C., \& Anto, J. J. (2018). Instagram and other Social Media Applications: A Comparison. Research Journal of Humanities and Social Sciences, 9(1), 209-212.

Karim, S. (2014). Style and language of inequality in the movie, "The King's Speech." ENH Community Journal, 1(1), 66-72.

Li, V. (2017). Social media in English language teaching and learning. International Journal of Learning and Teaching, 3(2), 148-153. https://doi.org/10.18178/ijlt.3.2.148-153

Meeker, M. (2019). Internet Trends 2019.

Misauri, S. (2018). Analysis of Colloquial Expressions in Gold Digger Prank. Universitas Sumatera Utara.

Nyagaka, N. A., \& James, P. W. (2014). Language style in advertisement. Kampala University Research Journal, 1(1), 1-12.

Ratnasari, D., Hidayat, D. N., Alek, A., \& Defianty, M. (2019). Interpersonal Meaning Analysis of Indonesian Politicians ' Instagram Captions. Advances in Social Science, Education and Humanities Research, 408, 222-230.

Renkema, J. (2004). Introduction to Discourse Studies. John Benjamins Publishing Company.

Ross, J. N., \& Coleman, M. N. (2010). Gold digger or Video Girl: The salience of an emerging hip-hop sexual script. Culture Health \& Sexuality, 13(2), 157-171.

Stephens, D. P., \& Phillips, L. D. (2003). Freaks, gold diggers, divas, and dykes: The sociohistorical development of adolescent African American women's sexual scripts. Sexuality and Culture, 7, 3-49.

Westenberg, W. (2016). The influence of YouTubers on teenagers: A descriptive research about the role YouTubers play. University of Twente.

Zulaekho, S. (2011). Language styles of Muluk In Alangkah Lucunya Negeri Ini Movie. Universitas Diponegoro. 